\title{
The impact of Hydrogen on the intermediate oxygen clusters and diffusion in Fluorite Structured $\mathrm{UO}_{2+\mathrm{x}}$
}

Joseph M. Flitcroft ${ }^{a, b}$ Adam R. Symington, ${ }^{b}$ Marco Molinari, ${ }^{a,{ }^{*}}$ Nicholas A. Brincat, ${ }^{c}$ Nicholas $R$. Williams, ${ }^{c}$ and Stephen C. Parker ${ }^{b, *}$

${ }^{\text {a} U n i v e r s i t y ~ o f ~ H u d d e r s f i e l d, ~ D e p a r t m e n t ~ o f ~ C h e m i s t r y, ~ U n i v e r s i t y ~ o f ~ H u d d e r s f i e l d, ~ Q u e e n s g a t e, ~}$ Huddersfield, HD1 3DH, UK

${ }^{b}$ University of Bath, Department of Chemistry, University of Bath, Bath, BA2 7AY, UK

${ }^{\mathrm{c} A W E}$ plc, Aldermaston, Reading, Berkshire, RG7 4PR, UK

\begin{abstract}
Uranium dioxide is the most prevalent nuclear fuel. Defect clusters are known to be present in significant concentrations in hyperstiochoimetric uranium oxide, $\mathrm{UO}_{2+\mathrm{x}}$, and have a significant impact on the corrosion of the material. A detailed understanding of the defect clusters that form is required for accurate diffusion models in $\mathrm{UO}_{2+x}$. Using ab initio calculations, we show that at low excess oxygen concentration, where defects are mostly isolated oxygen interstitials, hydrogen stabilizes the initial clustering. The simplest cluster at this low excess oxygen stoichiometry, consists of a pair oxygen ions bound to an oxygen vacancy, namely the split-monointerstitial, resembling larger split interstitials clusters in $\mathrm{UO}_{2+\mathrm{x}}$. Our data shows that depending on local
\end{abstract}


hydrogen concertation, the presence of hydrogen stabiles this cluster over isolated oxygen interstitials.

Keywords: interstitialcy, uranium oxide, hydrogen, oxygen cluster, hydroxyl groups, nuclear fuel

\section{Introduction}

The role of hydrogen on diffusion in materials is often overlooked if not part of proton conduction. This is despite the presence of hydrogen having an impact on many materials properties $^{1-16}$. In proton conductors, the behaviour of hydrogen at the atomistic level will define their microscopic conductivity. In fluorite structured materials this is relatively unclear, and so there is a compelling argument to map the interaction of hydrogen with the different components of the lattice. Detecting hydrogen experimentally is somewhat complex so modelling has become a routine way to analyse the details at the nanoscale ${ }^{17-22}$. Our research focusses on mapping the interaction between hydrogen and oxygen; the diffusion of hydrogen may indeed be affected by the diffusion of oxygen. One such diffusion mechanism is via the interstitialcy mechanism in which an interstitial anion displaces a lattice anion. This is particularly important in anion rich materials, such as found in the most important nuclear fuel, $\mathrm{UO}_{2+\mathrm{x}}$ In $\mathrm{UO}_{2}$ the corrosion of the material occurs via complex oxygen defect clustering ${ }^{1-10}$, as the oxygen stoichiometry within the material evolves over the fuel cycle, although the fluorite structure is retained over a wide oxygen stoichiometry resulting in many nonstoichiometric oxide phases existing between $\mathrm{UO}_{2}$ and $\mathrm{U}_{3} \mathrm{O}_{8}{ }^{10-}$ 12,23. However the impact of hydrogen on the clustering and thus on the diffusion of oxygen is still highly overlooked and yet the work on uranium corrosion ${ }^{24-26}$ shows that it is both present and diffuses through the oxide. 
The current consensus on $\mathrm{UO}_{2+x}$ oxidation agrees that below $x=0.05^{7}$ excess oxygen exists as isolated oxygen interstitials $\left(\mathrm{O}_{i}\right)$. Above $x=0.05$ clustering of oxygen interstitials and vacancies starts to occur, although its nature is still debated. Experimentally, the smallest cluster proposed is the Willis cluster ${ }^{27}$, however, all subsequent ab initio studies on its isolated form have found this to be unstable with respect to the split di-interstitial ${ }^{28}$. Recent $a b$ initio studies have shown that chains of Willis clusters are stable ${ }^{23}$ at $0.125<x<0.25$, and that hydrogen can stabilise isolated Willis clusters ${ }^{17}$. As the excess oxygen concentration continues to increase, larger defect clusters have been proposed, the cuboctahedron ${ }^{4,29}$ and the split interstitials $\mathrm{s}^{6,11,23,30,31}$.

In this study we have evaluated the thermodynamic stability of a new oxygen defect cluster at low excess oxygen concentrations. Our findings show that even at excess oxygen concentrations of $x<0.05$, it is possible for isolated oxygen interstitials to form a small stable defect clusters, which resembles the intermediate state of the interstitialcy diffusion of oxygen (Fig 1b), where a lattice oxygen diffuses by pushing another oxygen atom from its lattice site. As this cluster has a single excess oxygen, it can be referred to as a split-monointerstitial, $I_{1}^{x}$ (Fig. 1b) in line with common nomenclature for the family of split interstitials, where the split di-, tri- and quadinterstitials have 2, 3 or 4 additional oxygen atoms, respectively.

\section{Computational Methodology}

We have used $a b$ initio modelling at the density functional theory level. Four different sized simulation cells containing $12,16,24$ or $32 \mathrm{UO}_{2}$ units were generated in order to evaluate the stability of oxygen defects as a function of concentration. All calculations were performed using the VASP $\operatorname{code}^{32}$, with PAW pseudo-potentials and the GGA PBE $+U$ functional ${ }^{33}$. The Dudarev ${ }^{34}$ approach was used for the implementation of the onsite Hubbard $U_{\text {eff }}$ parameter, with $U=4.5 \mathrm{eV}$ and $J=0.54 \mathrm{eV}^{35}$, consistant with previous studies ${ }^{6,11-12,17,19}$. For the 12,16 and $24 \mathrm{UO}_{2}$ cells the 
plane-wave cut-off energy was set at $500 \mathrm{eV}$ and a $\Gamma$-centred $4 \times 4 \times 4$ Monkhorst-Pack $k$-point grid was used, whereas for the 32 unit $\mathrm{UO}_{2}$ cell the cut-off energy was $400 \mathrm{eV}$ and a $\Gamma$-centred $2 \times 2 \times 2$ Monkhorst-Pack $k$-point grid was used, in line with previous work ${ }^{17,18,30,36}$. The different sized simulating cells results in a consistent shift to the absolute energies of the defects but the relative energies remain the same, even with the inclusion of spin orbit-coupling ${ }^{18}$. In line with we use the 96 atom unit cell for all our simulations 6, 11-12, 17, $19^{\text {. }}$

For all calculations, convergence criteria for the electronic and ionic relaxations were $1 \times 10^{-6}$ $\mathrm{eV} /$ atom and $1 \times 10^{-2} \mathrm{eV} / \AA$, respectively. All calculations were performed at constant pressure to avoid any residual strain/stress on the defect cluster. All calculations implemented collinear $l k$ antiferromagnetic ordering, which is considered an appropriate approximation for the experimentally observed $3 k$ noncollinear antiferromagnetic ordering ${ }^{37,38}$, and is line with the literature ${ }^{4,23,30,36}$. The effect of spin orbit coupling has not been included as discussed in the

literature $^{18,39-41}$. In line with previous DFT studies the zero point energy (ZPE) was not included in the energy terms $6,19,31,38,42$.

All structural models were generated using the METADISE ${ }^{43}$ code and all structural figures were created using VESTA ${ }^{44}$.

\section{Results and Discussion}

For all structural models, including the isolated $\mathrm{O}_{i}$ and the $I_{1}^{x}$, one excess oxygen was added to the simulation cells producing four different excess oxygen stoichiometries (i.e. $\mathrm{UO}_{2+\mathrm{x}}$ with $\mathrm{x}=$ $0.03,0.04,0.06$ and 0.08 ) in the $12,16,24$ and $32 \mathrm{UO}_{2}$ cells, respectively. The $\mathrm{O}_{i}$ is at the centre of the octahedral interstitial site (Fig. 1a), whereas in the $I_{1}^{x}$ an interstitial displaces a lattice oxygen, thereby making the lattice oxygen an interstitial (Fig. 1b). The two oxygen atoms which 
form the $I_{1}^{x}$ cluster are displaced an average of $1.20 \AA$ in the $<110>$ direction from the vacancy site and $0.73 \AA$ in $\mathrm{a}<100>$ direction (Fig. 1b).

The formation energy of both the $I_{1}^{x}$ and $\mathrm{O}_{\mathrm{i}}$ was calculated according to Equation 1, where $E_{U O_{2+x}}$ is the energy of defective hyperstoichiometric $\mathrm{UO}_{2}, E_{U_{2}}$ is the energy of the stoichiometric $\mathrm{UO}_{2}$ and $E_{O_{2}}$ is the energy of oxygen gas.

$$
E_{F o r m}^{O}=E_{U O_{2+x}}-\left(E_{U O_{2}}+\frac{x}{2} E_{O_{2}}\right)
$$

Only at the lower excess oxygen concentrations $(\mathrm{x}<0.04)$ does the $I_{1}^{x}$ cluster have a favourable formation energy, although it remains less favourable than $\mathrm{O}_{i}$ across all oxygen stoichiometries (Fig. 2a). Further comparison of the $\mathrm{O}_{i}$ with the larger defect clusters, split di-interstitial $\left(\mathrm{UO}_{2.06}\right)$ and the split tri-interstitial $\left(\mathrm{UO}_{2.09}\right)^{30}$, shows that while the isolated $\mathrm{O}_{i}$ has a favourable formation energy they are now less favourable than the split interstitial clusters. The calculated energetics of the defects agrees with the current consensus for the oxidation model of $\mathrm{UO}_{2}$ where below $x=0.05$ oxygen exists as isolated $\mathrm{O}_{i}$ and above this clustering is preferred.

The introduction of an additional oxygen to the largest $\mathrm{UO}_{2}$ simulation cell resulted in the oxidation of two $\mathrm{U}^{4+}$ to $\mathrm{U}^{5+}$. For the $\mathrm{O}_{\mathrm{i}}$ this is accompanied by a reduction in volume of $-0.36 \%$. However, for the $I_{1}^{x}$ cluster there was an expansion in volume of $0.18 \%$. This provides a potential metric by which the $\mathrm{O}_{\mathrm{i}}$ and $I_{1}^{x}$ cluster can be differentiated.

As was shown in our previous work, the presence of small concentrations of hydrogen has a significant effect on the overall stability of the oxygen defect clusters such as the split di interstitial and the 2:2:2 Willis cluster ${ }^{17}$. We have therefore considered the impact of hydrogen on the stability of the $\mathrm{O}_{i}$ and the $I_{1}^{x}$ cluster, by varying the local hydrogen concentration between 117 and $234 \mu \mathrm{g}$ $\mathrm{H} / \mathrm{g} \mathrm{UO}_{2}$. This is equivalent to the addition of 1 and 2 hydrogen atoms to the simulation cell, respectively. The excess oxygen concentration was held constant at $x=0.03$, which corresponds to 
working with the simulation cell with $32 \mathrm{UO}_{2}$ units. All interstitial hydrogen was added as neutral defects, this allows for the preferred electronic distribution to occur. Addition of hydrogen, not in the presence of excess oxygen results in $\mathrm{H}^{-} / \mathrm{U}^{5+}$ or $\mathrm{H}^{+} / \mathrm{U}^{3+}$ defect pair depending on the distance between hydrogen and a lattice oxygen ${ }^{18-20}$. In the presence of excess oxygen an $\mathrm{OH}^{-} / \mathrm{U}^{5+}$ defect pair forms, where the hydrogen reduces one of the two $\mathrm{U}^{5+}$ formed by the excess oxygen ${ }^{17}$. The presence of excess oxygen has modified the defect behaviour of hydrogen within $\mathrm{UO}_{2+\mathrm{x}}$, compared with stoichiometric $\mathrm{UO}_{2}$, where the defect chemistry now resembles that of stoichiometric heavier $\mathrm{AnO}_{2}(\mathrm{An}=\mathrm{Np}, \mathrm{Pu}, \mathrm{Am}, \mathrm{Cm})$, where the hydroxyl defect is preferentially formed and the hydride defect is unstable ${ }^{18-20}$. However, $\mathrm{UO}_{2}$ occupies a unique point in the $\mathrm{AnO}_{2}$ series, making further comparisons difficult as it is the only material to have both the hydride and hydroxyl defects as stable $^{18,20}$.

There are a range of studies in the literature concerning the interaction of hydrogen with actinide dioxide surfaces, either as $\mathrm{H}_{2}^{45,46}$ or water molecules ${ }^{47-49}$. These studies have also looked at the evolution of $\mathrm{H}_{2}$ from the surface and provide a source from which hydrogen could be incorporated into the bulk lattice. However, these studies only consider the surface chemistry but do not report formation of large clusters. 

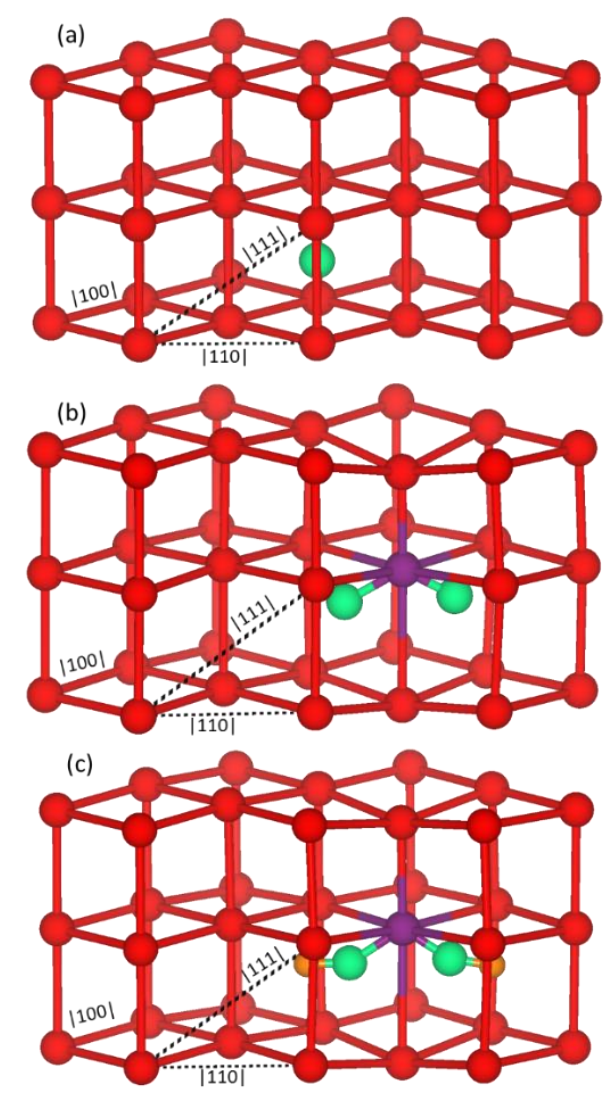

FIG. 1: (a) Oxygen interstitial location in the octahedral interstitial site. (b) Minimised $I_{1}^{x}$ configuration. (c) Minimised $I_{1}^{x}$ configuration with hydrogen present. Lattice oxygen shown in red, interstitial oxygen in green, oxygen vacancy in purple and hydrogen in orange. Uranium ions not shown for clarity.

The interaction of one $\mathrm{H}$ with the $\mathrm{O}_{i}$ resulted in the formation of a hydroxyl interstitial, whereas a H-O-H cluster (like a constrained water molecule with $\mathrm{H}-\mathrm{O}-\mathrm{H}$ bond angle of $87.13^{\circ}$ ) was formed when two $\mathrm{H}$ interacted with the $\mathrm{O}_{i}$ (all other configurations were the $2 \mathrm{H}$ interact with the $\mathrm{O}_{\mathrm{i}}$ and lattice oxygen were less stable). In the case of the $I_{1}^{x}$ cluster there are a greater variety of configurations for accommodating the interaction of hydrogen with the cluster. For the single hydrogen defect we considered two hydroxyl configurations; the first where one of the oxygen atoms of the $I_{1}^{x}$ forms a hydroxyl pointing towards the octahedral interstitial space and the second 
where the hydroxyl points towards the oxygen vacancy. When the hydrogen concentration doubled, we considered both oxygen of the $I_{1}^{x}$ forming hydroxyl groups and again these were both arranged to be pointing towards an octahedral interstitial site and both pointing towards the vacancy. Finally, we considered one pointing away and the other pointing towards the oxygen vacancy. The configuration of the $I_{1}^{x}$ cluster with the hydroxyl groups pointing away from the vacancy was significantly more favourable $\left(\approx 100 \mathrm{KJmol}^{-1}\right)$ than the other configurations, therefore this is the only configuration that we consider hereafter. This same behaviour is also observed between the larger defect clusters and hydrogen ${ }^{17}$.

The formation energy of defects interacting with hydrogen was calculated according to Equation 2, with $E_{U O_{2.00}}$ and $E_{U O_{2.03} H_{n}}$ the energy of stoichiometric $\mathrm{UO}_{2.00}$ and hydrogen doped oxygen rich $\mathrm{UO}_{2.03}, E_{\mathrm{H}_{2}}$ and $E_{\mathrm{O}_{2}}$ are the energies for molecular $\mathrm{H}_{2}$ and $\mathrm{O}_{2}$, respectively, with $n$ taking values of 0.03 or 0.06 , corresponding to 117 or $234 \mu \mathrm{g} \mathrm{H} / \mathrm{g} \mathrm{UO}_{2}$, respectively.

$$
E_{\text {Form }}^{O H}=E_{U O_{2.03} H_{n}}-\left(E_{U O_{2}}+\frac{0.03}{2} E_{O_{2}}+\frac{n}{2} E_{H_{2}}\right)
$$

The results clearly show that all defective clusters were stabilised by the addition of hydrogen as shown in Fig. 2b. The presence of hydrogen stabilises the $I_{1}^{x}$ defect cluster, and the stability relative to $\mathrm{O}_{\mathrm{i}}$ increases with hydrogen concentration. Indeed, at the highest hydrogen concentration, the cluster stability exceeds that of $\mathrm{O}_{\mathrm{i}}$ and hence we predict that this will act to pin the oxygen diffusion. The onset of this occurs when local hydrogen concentration is $117 \mu \mathrm{g} \mathrm{H} / \mathrm{g}$ $\mathrm{UO}_{2}$ (Fig. 2b). 

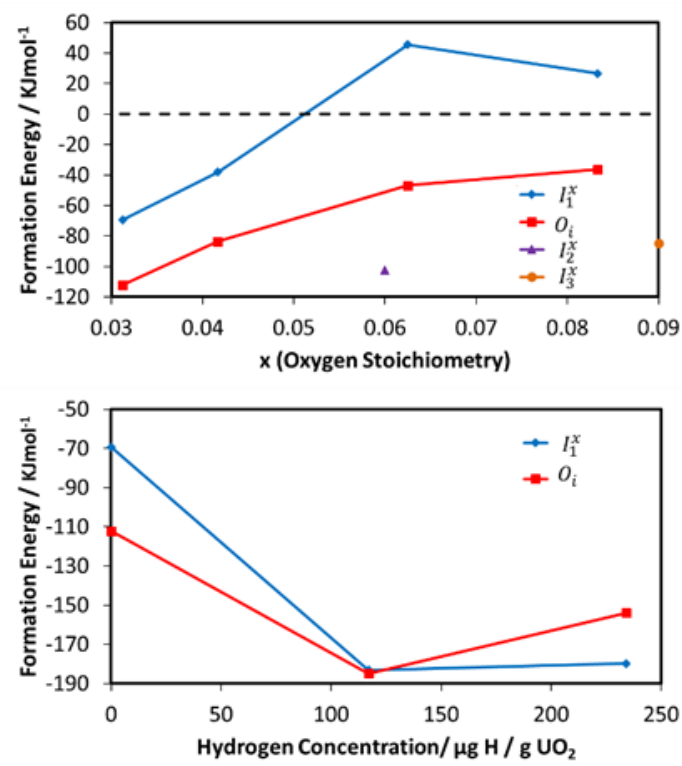

(b)

FIG. 2: (a) Solution energies of an oxygen interstitial and the $I_{1}^{x}$ cluster at varying excess oxygen concentrations. The defect clusters energetics represent the energy per $\mathrm{O}$ atom of a $I_{2}^{x}$ (split diinterstitial, 2.06) and $I_{3}^{x}$ (split tri-interstitial, 2.09), (b) Formation energies of oxygen interstitials and the $\mu \mathrm{g} \mathrm{H} / \mathrm{g} \mathrm{UO}_{2}$ cluster with varying hydrogen concentration. The excess oxygen concentration was constant at $x=0.03$. Only energies for the most stable configurations are shown.

An important contribution to the stability on the addition of hydrogen is through the reduction of $\mathrm{U}^{5+}$ introduced by the oxidation of $\mathrm{UO}_{2}$ (i.e. the presence of additional oxygen). One $\mathrm{U}^{5+}$ species is reduced for every hydrogen atom added. Thus at the higher concentrations of hydrogen ( $234 \mu \mathrm{g}$ $\mathrm{H} / \mathrm{g} \mathrm{UO}_{2}$ ), the uranium sublattice is made up entirely by $\mathrm{U}^{4+}$. This is associated with an expansion in volume for both the $\mathrm{O}_{\mathrm{i}}(0.65 \%)$ and $I_{1}^{x}(0.99 \%)$ thereby increasing chemical strain.

We have further calculated the relative probability of the defect clusters as a function of temperature, based on their formation energy, at the hydrogen concentrations considered in this 
work (Fig. 3). We have used the same approach as for our previous work on oxy-hydroxyl defect clusters in $\mathrm{UO}_{2}{ }^{17}$. Equation 3 displays the calculation of free energy, where $\Delta \mathrm{G}_{\mathrm{i}}$ is the free energy of the defect cluster $i, \Omega$ is the degeneracy of the cluster ( 1 for the all defects in this study), EForm,I os the formation energy calculated in equation 2 and we have recalled them such that this value is set to zero for the most stable defect, $R$ is the gas constant and $T$ is the temperature.

$$
\Delta G_{i}=\Omega e^{\left(\frac{-E_{F o r m, i}}{R T}\right)}
$$

The probability is then given by

$$
P=\frac{\Delta G_{i}}{\sum_{i} \Delta G_{i}}
$$

This approach does not explicitly include the effect of temperature on the differences between the defect free energies, but as the defects are all in the solid phase with similar size, symmetry and stability, the cohesive energy will dominate and entropic differences are unlikely to reverse the conclusions. However, the effect of entropic terms and explicit inclusion of temperature would be a useful area for future research.

In the absence of hydrogen the $\mathrm{O}_{i}$ is the dominant defect, up to temperatures of $3000 \mathrm{~K}$. When hydrogen is introduced (117 $\left.\mu \mathrm{g} \mathrm{H} / \mathrm{g} \mathrm{UO}_{2}\right)$, the probability of the clusters becomes near equal, with this time a slight favouring of the $\mathrm{O}_{i}$. Upon increasing the hydrogen concentration to $234 \mu \mathrm{g} \mathrm{H} / \mathrm{g}$ $\mathrm{UO}_{2}$ the $I_{1}^{x}$ cluster is now the most dominant defect. 


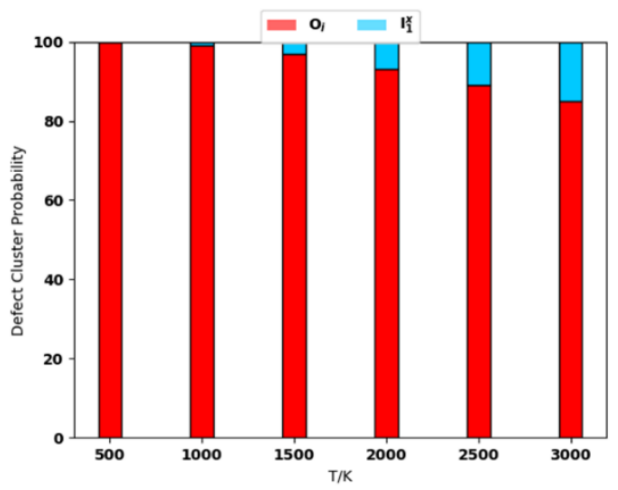

(a) $0 \mu \mathrm{g} \mathrm{H} / \mathrm{g} \mathrm{UO}_{2}$

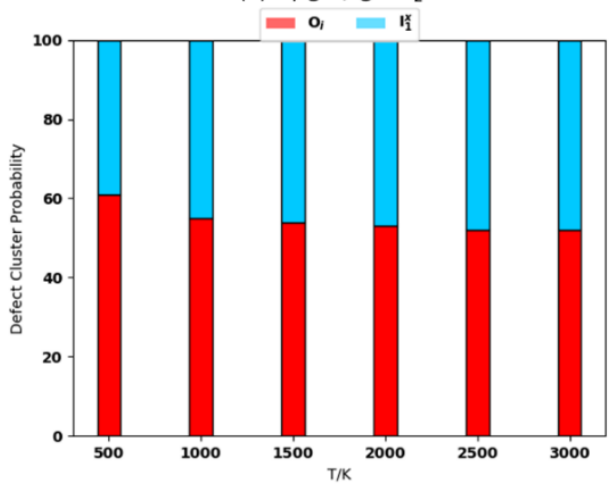

(b) $117 \mu \mathrm{g} \mathrm{H} / \mathrm{g} \mathrm{UO}_{2}$

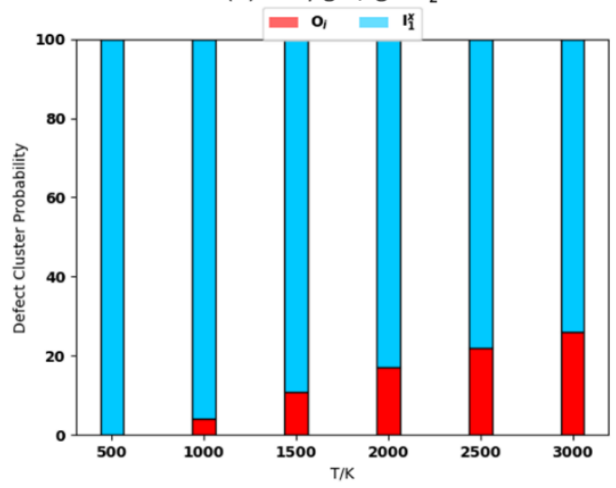

(c) $234 \mu \mathrm{g} \mathrm{H} / \mathrm{g} \mathrm{UO}_{2}$

FIG. 3: The relative probability of Oi or $I_{1}^{x}$ based cluster as a function of temperature assuming a fixed bulk concentration of hydrogen of (a) 0 , (b) 117 , (c), $234 \mu \mathrm{g} \mathrm{H} / \mathrm{g} \mathrm{UO}_{2}$. The probability has been calculated relative to the most stable cluster for each local hydrogen concentration.

The $I_{1}^{x}$ configuration represents the mid-point defect cluster of an interstitialcy diffusion mechanism $^{42}$, which is a metastable intermediary that can be called split mono interstitial. In the 
presence of hydrogen this cluster will have a similar formation energy compared to the isolated $\mathrm{O}_{\mathrm{i}}$; this will have implications for the understanding of the diffusion of oxygen in $\mathrm{UO}_{2}$. In the presence of hydrogen the $I_{1}^{x}$ cluster appears to be a relevant species that will compete to the $\mathrm{O}_{\mathrm{i}}$ diffusion and could immobilise the oxygen diffusing species. Although different oxygen clusters have been proposed for $\mathrm{UO}_{2+x}$ at different oxygen stoichiometry, isolated oxygen interstitials will still be the major diffusing species in oxygen rich environments, and so its diffusion will be moderated by the presence of hydrogen.

\section{Conclusions}

In conclusion, we have shown that oxygen clustering can occur at low excess oxygen concentrations in the fluorite structured $\mathrm{UO}_{2+\mathrm{x}}$, with the relative stability of the $\mathrm{O}_{i}$ and $I_{1}^{x}$ significantly affected by the presence of hydrogen. The $I_{1}^{x}$ becomes a relevant species, notably for crystallographic models that could explain the complex uranium-oxygen-hydrogen phase diagram and oxygen diffusion models of hyperstiochoimetric $\mathrm{UO}_{2}$. This will have implications in predicting and engineering the material's properties. There is room here for investigating other aspects to this work, notably whether this is a general behavior in fluorite materials, and the exploration of the migration barriers of oxygen diffusion in the presence of hydrogen. Finally, correlating our $a b$ initio data to experimental data from pair distribution function (PDF) analysis will provide essential insight into oxygen cluster behavior and should constitute the object of further work.

\section{Corresponding Author}

Correspondence should be directed to Stephen C. Parker (s.c.parker@bath.ac.uk) or Marco Molinari (M.Molinari@hud.ac.uk).

\section{Author Contributions}


The manuscript was written through contributions of all authors. All authors have given approval to the final version of the manuscript.

\section{Conflicts of interest}

There are no conflicts to declare.

\section{Acknowledgements}

This work made use of ARCHER, the UK's national HPC funded by EPSRC (EP/L000202, EP/R029431) through the Material Chemistry Consortium, Balena, the University of Bath's HPC. We thank AWE, the University of Bath, the University of Huddersfield (Orion) and EPSRC (EP/R010366/1, EP/R023603/1) for funding.

\section{References}

1. Allen, G. C.; Holmes, N. R., A mechanism for the $\mathrm{UO}_{2}$ to $\alpha-\mathrm{U}_{3} \mathrm{O}_{8}$ phase transformation, $J$. Nucl. Mater., 1995, 223, 231-237.

2. Allen, G. C.; Butler, I. S.; Tuan, N. A., Characterization of uranium oxides by microRaman spectroscopy, J. Nucl. Mater., 1987, 144, 17-19.

3. Wang J.; Ewing, R. C.; Becker, U., Average structure and local configuration of excess oxygen in $\mathrm{UO}_{2+x}$, Sci. Rep., 2014, 4, 4216.

4. Desgranges, L.; Baldinozzi, G.; Simeone, D.; Fischer, H. E., Structural Changes in the Local Environment of Uranium Atoms in the Three Phases of $\mathrm{U}_{4} \mathrm{O}_{9}$, Inorg. Chem., 2016, $55,7485-7491$. 
5. Leinders, G.; Delville, R.; Pakarinen, J.; Cardinaels, T.; Binnemans, K.; Verwerft, M., Assessment of the $\mathrm{U}_{3} \mathrm{O}_{7}$ Crystal Structure by X-ray and Electron Diffraction, Inorg. Chem., 2016, 55, 9923-9936.

6. Andersson, D. A. ; Espinosa-Faller, F.; Uberuaga B. P. ; Conradson, S. D.; Stability and migration of large oxygen cluster in $\mathrm{UO}_{2+\mathrm{x}}$ : Density functional theory calculations, $J$. Chem. Phys., 2012, 136, 234702.

7. Elorrieta, J. M.; Bonales, L. J.; Rodríguez-Villagra, N.; Baonzab, V. G.; Cobosa, A detailed Raman and X-ray study of $\mathrm{UO}_{2+x}$ oxides and related structure transitions, J., Phys. Chem. Chem. Phys., 2016, 18, 28209-28216.

8. Ma, Y.; Garcia, P.; Lechelle, J.; Miard, A.; Desgranges, L.; Baldinozzi, G.; Simeone, D.; Fischer, H. E., Characterization of Oxygen Defect Clusters in $\mathrm{UO}_{2+\mathrm{x}}$ Using Neutron Scattering and PDF Analysis, Inorg. Chem., 2018, 57, 7064-7076.

9. Hoekstra, H. R.; Santoro, A.; Siegel, S., The low temperature oxidation of $\mathrm{UO}_{2}$ and $\mathrm{U}_{4} \mathrm{O}_{9}$, J. Inorg. Nucl. Chem., 1961, 18, 154-165.

10. Hoekstra, H. R.; Siegel, S.; Gallagher, F. X., The Uranium-Oxygen System at High Pressure, J. Inorg. Nucl. Chem., 1970, 32, 3237-3248.

11. Andersson, D. A.; Baldinozzi, G.; Desgranges, L.; Conradson, D. R.; Conradson, S. D., Density Functional Theory Calculations of $\mathrm{UO}_{2}$ Oxidation: Evolution of $\mathrm{UO}_{2+\mathrm{x}}, \mathrm{U}_{4} \mathrm{O}_{9-\mathrm{y}}$, $\mathrm{U}_{3} \mathrm{O}_{7}$ and $\mathrm{U}_{3} \mathrm{O}_{8}$, Inorg. Chem., 2013, 52, 2769-2778. 
12. Brincat, N. A.; Parker, S. C.; Molinari, M.; Allen, G. C.; Storr, M. T., Density functional theory investigation of the layered uranium oxides $\mathrm{U}_{3} \mathrm{O}_{8}$ and $\mathrm{U}_{2} \mathrm{O}_{5}$, Dalton Trans., 2015, 44, 2613-2622.

13. Li, D.-G. Xie, E. Ma, J. Li, X.-X. Zhang and Z.-W. Shan, Effect of hydrogen on the integrity of aluminum-oxide interface at elevated temperatures, Nat. Commun., 2017, 8, 14564.

14. Norby, T.; Widerøe, M.; Glöcknera, R.; Larring, Y., Hydrogen in oxides, Dalton Trans., 2004, 0, 3012-3018.

15. Norby, T., The promise of protonics, Nature, 2001, 410, 877-878.

16. Malerød-Fjeld, H.; Clark, D.; Yuste-Tirados, I.; Zanón, R.; Catalán-Martinez, D.; Beeaff, D.; Morejudo, S. H.; Vestre, P. K.; Norby, T.; Haugsrud, R.; Serra, J. M.; Kjølseth, C., Thermo-electrochemical production of compressed hydrogen from methane with near-zero energy loss, Nature Energy, 2017, 2, 923-931.

17. Flitcroft, J. M.; Molinari, M.; Brincat, N. A.; Williams, N. R.; Storr, M. T.; Allen G. C.; Parker, S. C., The Critical Role of Hydrogen on the Stability of Oxy-Hydroxyl Defect Clusters in Uranium Oxide, J. Mater. Chem. A, 2018, 6, 11362-11369.

18. Flitcroft, J. M.; Molinari, M.; Brincat, N. A.; Storr, M. T.; Parker, S. C., Hydride Ion Formation in Stoichiometric $\mathrm{UO}_{2}$, Chem. Commun., 2015, 51, 16209-16212.

19. Bingyun, A.; Ruizhi, Q.; Haiyan, L.; Piheng, C., Difference in the Existence States of Hydrogen in $\mathrm{UO}_{2}$ and $\mathrm{PuO}_{2}$ from DFT+U Calcualtions, J. Phys. Chem. C, 2016, 120, $18445-18451$. 
20. Bingyun, A.; Ruizhi, Q.; Guangfen, Z.; Zhen, P.; Xiaolin, W.; Peng, S., Light impurity atoms as the probes for the electronic structures of actinide dioxides, Computational Materials Science, 2018, 142, 25-31.

21. Molinari, M.; Parker, S.C.; Sayle, D.C.; and M. S. Islam, Water Adsorption and Its Effect on the Stability of Low Index Stoichiometric and Reduced Surfaces of Ceria, J. Phys. Chem. C, 2012, 116, 7073-7082.

22. Tegner, B.E.; Molinari, M.; Kerridge, A.; Parker, S.C.; Kaltsoyannis, N., Water Adsorption on $\mathrm{AnO}_{2}\{111\},\{110\}$, and $\{100\}$ Surfaces $(\mathrm{An}=\mathrm{U}$ and $\mathrm{Pu})$ : A Density Functional Theory + U Study, J. Phys. Chem. C, 2016, 121, 1675-1682.

23. Brincat, N.A.; Molinari, M.; Allen, G.C.; Storr, M.T.; Parker, S.C., Density functional theory calculations of defective $\mathrm{UO}_{2}$ at $\mathrm{U}_{3} \mathrm{O}_{7}$ stoichiometry, J. Nucl. Mater., 2015, 467, 724-729.

24. Glascott, J., A model for the initiation reaction sites during the uranium-hydrogen reaction assuming enhanced hydrogen transport through thin areas of surface oxide, Philosophical Magazine, 2014, 94, 1393-1413.

25. Glascott, J.; A model for the initiation reaction sites during the uranium-hydrogen reaction assuming enhanced hydrogen transport through linear oxide discontinuities, Philosophical Magazine, 2014, 94, 221-241.

26. Stitt, C.A.; Harker, N.J.; Hallam, K.R.; Paraskevoulakpos, C.; Banos, A.; Rennie, S.; Jowset, J.; Scott, T.B., An Investigation on the Persistence of Uranium Hydride during the Storage of Simulant Nuclear Waste Packages, Plos One, 2015, 10, 1-13. 
27. Willis, B.T.M., Positions of the Oxygen Atoms in $\mathrm{UO}_{2.13}$, Nature, 1963, 197, 755-756.

28. Geng, H. Y.; Chen, Y.; Kaneta, Y.; Kinoshita, M., Ab initio investigations on oxygen defect clusters in $\mathrm{UO}_{2+\mathrm{x}}$, Appl. Phys. Lett., 2008, 93, 201903.

29. Bevan, D. J. M.; Grey, I. E.; Willis, B. T. M., The crystal structure of $\beta-\mathrm{U}_{4} \mathrm{O}_{9-\mathrm{y}}$, J. Solid State Chem., 1986, 61, 1-7.

30. Brincat, N. A.; Molinari, M.; Parker, S. C.; Allen, G. C.; Storr, M. T., Computer simulation of defect clusters in $\mathrm{UO}_{2}$ and their dependence on composition, J. Nucl. Mater., 2015, 456, 329-333.

31. Andersson, D.A.; Watanabe, T.; Deo, C.; Uberuaga, B.P., Role of di-interstitials clusters in oxygen transport in $\mathrm{UO}_{2+x}$ from first principles, Phys. Rev. B, 2009, 80, 060101(r)

32. Kresse, G.; Furthmuller, J., Efficient iterative schemes for ab initio total-energy calculations using a plane-wave basis set, Phys. Rev. B, 1996, 54, 11169-11186.

33. Perdew, J. P.; Burke, K.; Ernzerhof, M. Generalized Gradient Approximations Made Simple, Phys. Rev. Lett., 1996, 77, 3865-3868.

34. Castell, M. R., Surface structure and bonding in the strongly correlated metal oxides $\mathrm{NiO}$ and $\mathrm{UO}_{2}$, Journal of Vacuum Science \& Technology A: Vacuum, Surfaces, and Films, 1998, 16, 1055.

35. Yamazaki, T.; Kotani, A., Systematic Analysis of $4 f$ Core Photoemission Spectra in Actinide Oxides, J. Phys. Soc. Jpn., 1991, 60, 49-52. 
36. Andersson, D.A.; Lezama, J.; Uberuaga, B.P.; Deo, C.; Conradson, S.D., Cooperativity among defect sites in $\mathrm{AO}_{2+\mathrm{x}}$ and $\mathrm{A}_{4} \mathrm{O}_{9}(\mathrm{~A}=\mathrm{U}, \mathrm{Np}, \mathrm{Pu})$ : Density functional calculations, Phys. Rev. B, 2009, 79, 024110-024111.

37. Laskowski, R.; Madsen, G. K. H.; Blaha, P.; Schwarz, K., Magnetic structure and electricfield gradients of uranium dioxide: An ab initio study, 2004, Phys. Rev. B, 69, 1404081.

38. Dorado, B.; Jomard, G.; Freyss, M; Bertolus, M., Stability of oxygen point defects in $\mathrm{UO}_{2}$ by first-principles DFT $+U$ calculations: Occupation matrix control and Jahn-Teller distortion, Phys. Rev. B, 2010, 82, 0351141-0351141.

39. Bottin, F.; Geneste, G.; Jomard, G., Thermodynamic stability of the $\mathrm{UO}_{2}$ surfaces: Interplay between over-stoichiometry and polarity compensation, Phys. Rev. B, 2016, 93, 115438.

40. Santini, P.; Lemanski, R.; Edros, P., Magnetism of actinide compounds, Advancing Physics, 1999, 537-653.

41. Wen, X.-D.; Martin, R. L.; Roy, L. E.; Scuseria, G. E.; Rudin, S. P.; Batista, E. R.; McCleskey, T. M.; Scott, B. L.; Bauer, E.; Joyce, J. J.; Durakiewicz, T., Effect of spinorbit coupling on the actinide dioxides $\mathrm{AnO}_{2}(\mathrm{An}=\mathrm{Th}, \mathrm{Pa}, \mathrm{U}, \mathrm{Np}, \mathrm{Pu}$, and $\mathrm{Am})$ : a screened hybrid density functional study, J. Chem. Phys., 2012, 137, 154707

42. Dorado, B.; Garcia, P.; Carlot, G.; Davoisne, C.; Fraczkiewicz, M.; Pasquet, B.; Freyss, M.; Valot, C.; Baldinozzi, G.; Simeone, D.; Bertolus, M., First-principles calculations and experimental study of oxygen diffusion in uranium dioxide, Phys. Rev. B, 2011, 83, 035126. 
43. Watson, G.W.; Kelsey, E. T.; deLeeuw, N. H.; Harris, D. J.; Parker, S. C., Atomistic simulation of dislocations, surfaces and interfaces in MgO, J. Chem. Soc., Faraday Trans., 1996, $92,433-438$.

44. Momma, K.; Izumi, F., VESTA: a three-dimensional visualization system for electronic and structural analysis, Journal of Applied Crystallography, 2008, 41, 653-658.

45. Bo T, Lan J-H, Wang C-Z, Zhao Y-L, He C-H, Zhang Y-J, et al. First-Principles Study of Water Reaction and $\mathrm{H}_{2}$ Formation on $\mathrm{UO}_{2}$ (111) and (110) Single Crystal Surfaces. J Phys Chem C. 2014;118(38):21935-44.

46. Zhang, C.; Yang, Y.; Zhang, P., Thermodynamics of dehydrating Reaction on the $\mathrm{PuO}_{2}$ (110) Surface from First Principles, J. Phys. Chem. C, 2018, 122, 7790-7794

47. Zhang, C.; Yang, Y.; Zhang, P., Dissociation Mechanism of Water Molecules on the $\mathrm{PuO}_{2}(110)$ Surface: An Ab Initio Molecular Dynamic Study, J. Phys. Chem. C, 2018, 122, $371-376$

48. Tegner, B.E.; Kaltsoyannis, N., Multiple Water Layers on $\mathrm{AnO}_{2}\{111\},\{110\}$, and $\{100\}$ surfaces $(\mathrm{An}=\mathrm{U}, \mathrm{Pu})$ : A computational study, J. Vac. Sci. Technol. A, 2018, 041402

49. Bo T, Lan J-H, Zhao Y-L, Zhang Y-J, He C-H, Chai Z-F, et al. First-Principles Study of Water Adsorption and Dissociation on the $\mathrm{UO}_{2}$ (111), (110) and (100) Surfaces. J Nuc. Mater. 2014;454(1):446-54. 
For Table of Contents Only.

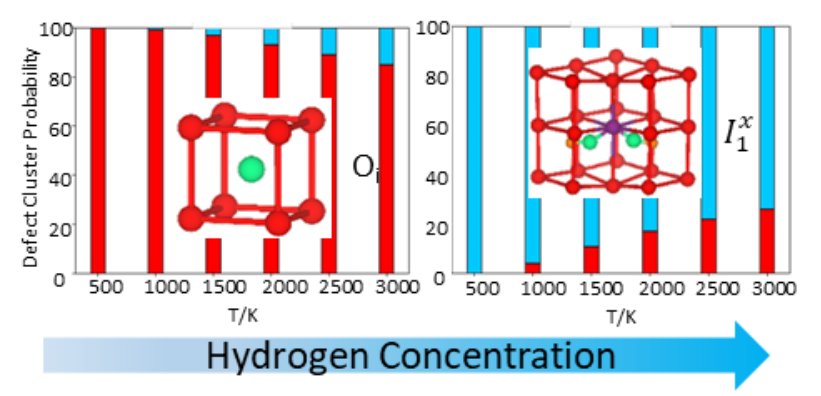

We used DFT simulations to model the incorporation of hydrogen in oxygen rich $\mathrm{UO}_{2}$. The results suggest that an intermediate oxygen cluster is stabilised by the hydrogen. As this cluster represents an intermediate on the oxygen diffusion pathway, hydrogen may disrupt oxygen transport in this important nuclear material. 